\title{
Orthotics for Easter
}

Nguyen Dang Thuong

With a body sewn up just last night assembled with a pig's heart a cow's lungs nylon hair fake teeth $\&$ hands from a corpse of a white serial killer \& facial skin grafted from a buttock \& limbs of pink plastic bones \& flesh \& an all-seeing eye my brain is a computer chip I design programs of lasting happiness for the future I look back at my life $\mathrm{O}$ it is so new so gorgeous so perfect I'm grateful $\mathrm{O}$ danke schön herr doktor frankenstön

Translated by Linh Dinh 